\title{
Correction to: NetConfer: a web application for comparative analysis of multiple biological networks
}

Sunil Nagpal ${ }^{1}$, Krishanu Das Baksi ${ }^{1}$, Bhusan K. Kuntal ${ }^{1,2,3^{*}}$ and Sharmila S. Mande ${ }^{1 *}$

\section{Correction to: BMC Biol 18, 53 (2020) \\ https://doi.org/10.1186/s12915-020-00781-9}

Following publication of the original article [1], the authors identified an error in the affiliation list. Affiliation 3 was incorrectly processed as:

Academy of Scientific and Innovative Research (AcSIR), CSIR-National Chemical Laboratory Campus, Pune 411 008, India.

Affiliation 3 should have been processed as:

Academy of Scientific and Innovative Research (AcSIR), Ghaziabad 201002, India.

The corrected affiliation list is reflected in this Correction.

\section{Author details}

'Bio-Sciences R\&D Division, TCS Research, Tata Consultancy Services Ltd., 54-B Hadapsar Industrial Estate, Pune 411 013, India. ${ }^{2}$ Chemical Engineering and Process Development Division, CSIR-National Chemical Laboratory, Dr. Homi Bhabha Road, Pune 411 008, India. ${ }^{3}$ Academy of Scientific and

Innovative Research (AcSIR), Ghaziabad 201002, India.

Published online: 22 October 2020

\section{Reference}

1. Nagpal, et al. NetConfer: a web application for comparative analysis of multiple biological networks. BMC Biol. 2020;18:53 https://doi.org/10.1186/ s12915-020-00781-9.

The original article can be found online at https://doi.org/10.1186/s12915020-00781-9.

* Correspondence: kuntal.bhusan@tcs.com; sharmila.mande@tcs.com

'Bio-Sciences R\&D Division, TCS Research, Tata Consultancy Services Ltd., 54-B Hadapsar Industrial Estate, Pune 411 013, India

Full list of author information is available at the end of the article

C C The Author(s). 2020 Open Access This article is licensed under a Creative Commons Attribution 4.0 International License, which permits use, sharing, adaptation, distribution and reproduction in any medium or format, as long as you give appropriate credit to the original author(s) and the source, provide a link to the Creative Commons licence, and indicate if changes were made. The images or other third party material in this article are included in the article's Creative Commons licence, unless indicated otherwise in a credit line to the material. If material is not included in the article's Creative Commons licence and your intended use is not permitted by statutory regulation or exceeds the permitted use, you will need to obtain permission directly from the copyright holder. To view a copy of this licence, visit http://creativecommons.org/licenses/by/4.0/ The Creative Commons Public Domain Dedication waiver (http://creativecommons.org/publicdomain/zero/1.0/) applies to the data made available in this article, unless otherwise stated in a credit line to the data. 